\title{
Issues and challenges of reclaimed water usage: a case study of the Dragon-shaped River in the Beijing Olympic Park
}

\author{
Xiaoqin Zhou ${ }^{1}$, Zifu $\mathrm{Li}^{1 *}$, Chad Staddon ${ }^{2}$, Xuejun $\mathrm{Wu}^{3}$, Han Song ${ }^{3}$ \\ ${ }^{1}$ School of Energy and Environmental Engineering, Beijing Key Laboratory of \\ Resource-oriented Treatment of Industrial Pollutants, University of Science and Technology \\ Beijing, Beijing 100083, PR China \\ ${ }^{2}$ International Water Security Network, University of the West of England, Bristol, UK \\ ${ }^{3}$ Beijing I \& Earth Environmental Protection Engineering Co., Lid. Beijing 100083, PR China
}

\begin{abstract}
Increased use of reclaimed water could be one of the solutions to Beijing's growing water shortage, particularly for non-potable (e.g. landscaping) purposes. The 'Dragon-shaped River', a large artificial waterscape built on the site of the 2008 Beijing Olympic games, offers a useful case study of the issues and challenges attendant on wastewater reclamation and reuse. Of particular interest is the use of phytoremediation techniques for bioremediation of nutrient loads. This paper presents the results of ongoing monitoring which indicates that phytoremediation is succeeding in preventing eutrophication, though some challenges, notably management of aquatic biomass, remain.
\end{abstract}

Key words: Dragon-shaped River; phytoremediation; submerged plants; reclaimed water

\section{Introduction}

With increasing population, urbanization and climate change, water shortages are now 
appearing all over the world, including in China's capital city Beijing. In an average year, Beijing has available 2,680 million cubic meters of water from existing sources, which is equivalent to about 123.8 cubic meters per capita, making Beijing a 'water stressed' city by international standards (NBSC National Bureau Of Statistics Of China, 2016; Staddon, 2010). Water experts are therefore developing multiple alternative water resources to help address this imbalance. Currently there are four main water resources for water supply into Beijing: surface water, ground water, the South-North water transfer scheme and reclaimed water, accounting for $13 \%, 55 \%, 10 \%$ and $22 \%$ of total available resources respectively (Jensen \& Yu, 2016). The 22\% of water supply provided through wastewater reclamation in 2013 amounted to around 860 million cubic meters and is expected to rise to 1,200 million cubic meters by 2020 as new schemes are completed. Wastewater reuse is clearly a key part of Beijing's future water balance.

Reclaimed water reuse is receiving more and more attention from water specialists, with well-known and successful systems in place in locations as diverse as Windhoek, Namibia and Singapore (Bixio et al., 2006; Jensen \& Yu, 2016; Staddon, 2010). These are systems for direct potable reuse of treated wastewater however and there are many, many more examples of non-potable wastewater reuse. Non-potable wastewater reuses can include irrigation, industrial cooling water, car washing, landscape irrigation as well as ecological/environmental supplementation during periods of low base flow. Reclaimed water quality can be an issue however. Physical and chemical contaminants such as $\mathrm{pH}$, chemical oxygen demand (COD), total phosphorus (TP) and total nitrogen 
(TN), as well as microbial contamination, need to be reduced to below regulatory norms before even non-potable use is possible (Bixio et al., 2006; Salgot et al., 2006; Huertas et al., 2008). In 2000 quality standards for reclaimed water for non-potable use were published by the Chinese government, and these standards have been revised several times since (Yi et al., 2011). Current standards stipulate that $\mathrm{BOD}_{5}($ Biological Oxygen Demand calculated by the five day method) should be below $6 \mathrm{mg} / \mathrm{L}$, total nitrogen should be below $15 \mathrm{mg} / \mathrm{L}$, and total phosphorus should not exceed $0.5 \mathrm{mg} / \mathrm{L}$. Even within these standards however, there remains a risk of eutrophication in certain circumstances (Soyupak et al., 1997). Moreover, the complex structure of water quality regulation (with multiple departments exercising control over different sources of wastewater and different potential end uses) makes regulatory compliance challenging (Jensen and Yu, 2016). Therefore, reclaimed water reuse faces both technical and regulatory challenges (Liu \& Persson, 2013).

As host of the $29^{\text {th }}$ Olympic Summer Games in summer 2008, China strongly promoted the concept of a high-tech and environmentally sustainable games, and the games venues themselves were designed to showcase Chinese developments in sustainable urbanisation including reclaimed water utilization and rainwater harvesting (Jensen \& Yu, 2016). In particular, the main Olympic site master plan included a specially built wastewater treatment plant, linked to a series of slow-flow water bodies which together form a semi-natural ecosystem - the 'Dragon-shaped River' - which terminates in the 'Dragon Lake', now considered a beauty and biodiversity hotspot. In this study, we focus on the use of phytoremediation to address eutrophication pressures in the 
Dragon-shaped River.

\section{An Overview of the Water Quality Situation of the Dragon-shaped River at Beijing Olympic Park}

The Beijing Olympic Park was the main location for the games, and many of its structures (such as the 'Bird's Nest' and the 'Water Cube') have become iconic buildings. Of particular interest to water managers and scholars is the artificial river/lake complex shaped like a dancing dragon which was designed to provide a semi-natural structure integrating the Olympic site along a north-south axis (Figure 1).

As is shown in Figure 1, the head of the dragon forms the central water feature of the

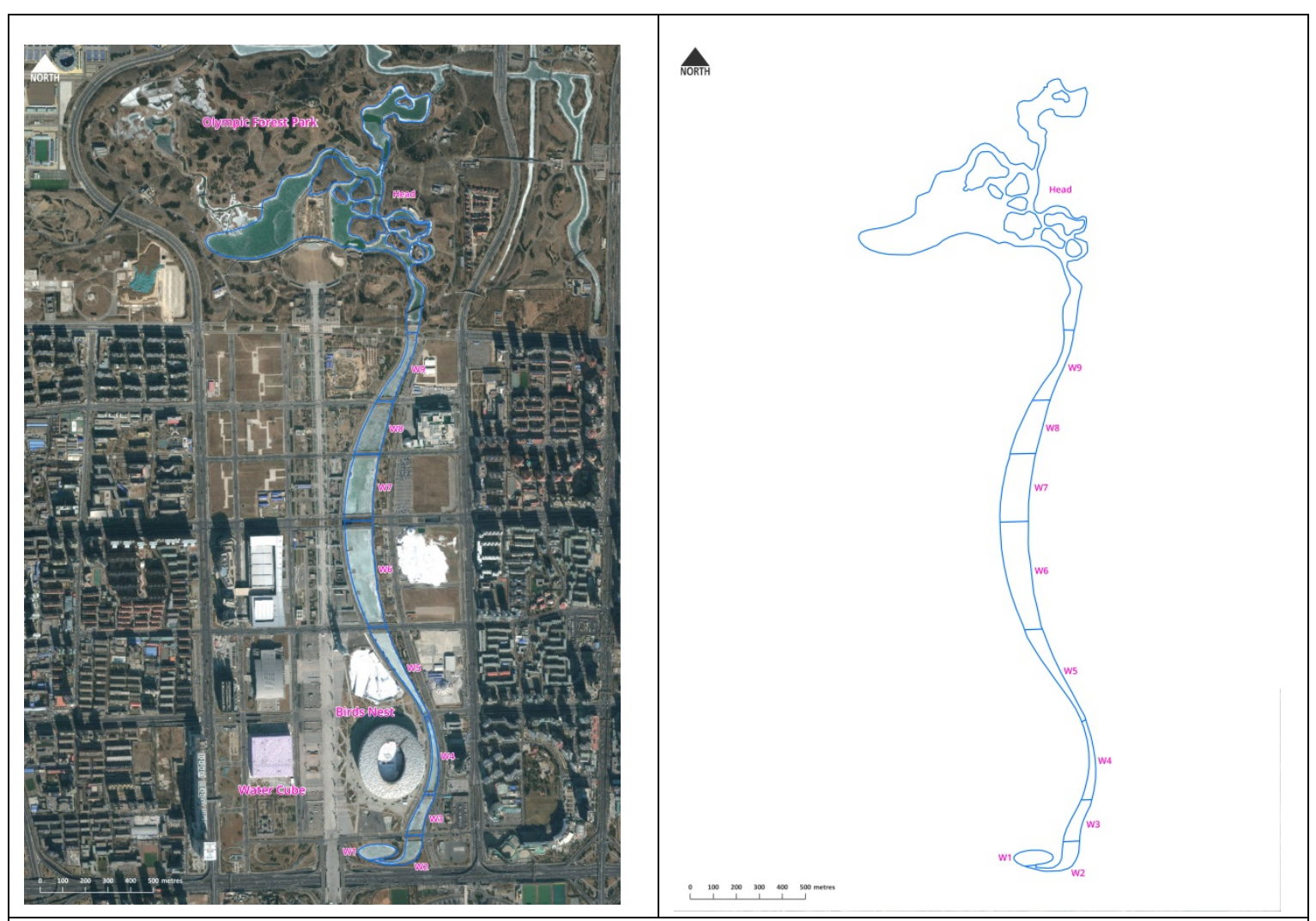

Figure 1: Main Beijing Olympic Site, showing Dragon-shaped River system, with Dragon Lake and Olympic Forest Park at top. Source: Paul Satchell, UWE, Bristol

'Olympic Forest Park' at the northern end of the site, the body runs down the eastern side of the park, and the tail coils around the National Stadium (the 'Bird's Nest') at the 
southern extremity. The watershed in the Olympic Park is the world's largest artificial landscape using reclaimed water as the sole water source with a total water surface area of $842,000 \mathrm{~m}^{2}\left(0.842 \mathrm{~km}^{2}\right)$, and a total water storage capacity of 1.3 million cubic meters.

Of this total surface area, the main Dragon-shaped River and lake structures occupy $485,000 \mathrm{~m}^{2}$ and have a total water storage capacity of 0.75 million metres ${ }^{3}$. The Dragon-shaped River itself is $2.7 \mathrm{~km}$ in length, 20-125 m wide, and its depth varies from about $0.6-1.2 \mathrm{~m}$. The river is divided into nine individual sections by eight road bridges, with each section connected by an underground culvert. Water flows from northwards from the first section (the tail of the dragon, labelled as W1 in Figure 1) to the last section (the neck of the dragon, labelled W9). The water level gradually becomes deeper from the edges inward towards the center, but only to a maximum depth of $1.24 \mathrm{~m}$ at its deepest point in section W8.

The amount and frequency of reclaimed water inflow varies considerably, for example between 56,000 to $100,000 \mathrm{~m}^{3} / \mathrm{d}$ from April to October 2013. Despite this variability key nutrients (TN, TP, $\mathrm{NH}_{3}-\mathrm{N}$ ) of reclaimed water usually meet the wastewater quality standards for 'scenic water' in China. During normal operation, no untreated wastewater is discharged into the river, but non-point contamination does arrive as a function of surface water runoff. However, this only contributes $4.04 \%$ of the TN, $15.2 \%$ of the TP, $8.17 \%$ of the COD and $14.47 \%$ of the $\mathrm{NH}_{3}-\mathrm{N}$ loading. The issues related to non-point source contamination are not specifically discussed in this paper. By 2010, signs of eutrophication were appearing: floating (organic) material was 
reported in the Dragon-shaped River and there were growing numbers of complaints about the smell from the water. The most likely explanation for this was that reclaimed water relatively high in nitrogen and phosphate combined together with the shallow water level, the low-velocity water flow from $\mathrm{W} 1$ to $\mathrm{W} 9$, and sufficient sunshine reaching the bottom of the shallow sections to create perfect conditions for algal and microbial overgrowth along with the foul smell - in other words, eutrophication was occurring.

Table 1: Main chemical parameters of reclaimed water at the W1 inlet (samples were taken in June, 2014)

\begin{tabular}{cccccc}
\hline $\mathrm{pH}$ & $\begin{array}{c}\mathrm{NH}_{3}-\mathrm{N} \\
(\mathrm{mg} / \mathrm{L})\end{array}$ & $\begin{array}{c}\mathrm{TN} \\
(\mathrm{mg} / \mathrm{L})\end{array}$ & $\begin{array}{c}\mathrm{TP} \\
(\mathrm{mg} / \mathrm{L})\end{array}$ & $\begin{array}{c}\mathrm{COD} \\
(\mathrm{mg} / \mathrm{L})\end{array}$ & $\begin{array}{c}\text { Turbidity } \\
(\mathrm{NTU})\end{array}$ \\
\hline 7.15 & 0.76 & 10.8 & 0.41 & $36(\mathrm{Cr})$ & 1.03 \\
\hline
\end{tabular}

In order to improve this situation, aquatic plants were placed in the nine sections to promote phytoremediation of nutrients and thereby reduce eutrophication. The process had three steps: cleaning the river channel of algal biomass, planting submerged plants according to a carefully planned scheme and the operation, monitoring and management of the resulting enhanced water system. In the first step, the river channel was cleared of weeds and microorganisms were added to reactivate bottom sediments in order to form a benthic microbial degradation system. In the second step, submerged plants were selected and planted in the nine sections in carefully calculated ratios and densities. The selection of the plants was based on the measured contamination levels and a review of secondary literature on phytoremediation. This literature (e.g. Gross et al, 2003; Hilt and Gross, 2008) suggests that plants such as Ceratophyllum demersum L. (Hornwort), and Najas marina L. (Spiny Water Nymph) release allelochemicals that inhibit anaerobic decomposition, a primary cause of foul smells and turbidity. These plants and also 
plants from the Elodea (Waterweed) and Potamogetonaceae (Pondweed) families can be assembled into clumps or complexes that work together in the river, with different allelochemicals released by different plants, so that most kinds of harmful algae are inhibited. (Körner and Nicklisch, 2002). Such constructed plant communities can also inhibit the production of harmful types of cyanobacteria. In the final step, a monitoring programme was put in place to assess the contribution of each basin to phytoremediation of target pollutants (TN, TP, COD).

The ecological engineering was completed by the end of 2010. The monitoring began two years later and, from April 2013 to July 2014, samples were taken in each of the nine segments (Figure 1, W1 to W9) twice per month, at about $0.1 \mathrm{~m}$ below the surface, except during winter, when the surface freezes. The water quality parameters measured include COD, total nitrogen (TN), ammonia $\left(\mathrm{NH}_{3}-\mathrm{N}\right)$, and total phosphorus (TP) and sample analyses were conducted in accordance with the methods described in the state

publication "Water and Wastewater Monitoring and Analysis Method' (State Environmental Protection Administration of the People’s Republic of China, 2002). All the monitoring data was analysed, and graphics generated, using Origin 9.0.

\section{Measured Impact of Phytoremediation}

\subsection{Landscape effects before and after planting}

The scenic landscape value improved considerably after the introduction of the submerged plants. Beforehand the water looked green with grey suspended solids and poor transparency, as well as the much-commented upon foul smells. Afterwards, the 
water was clear enough to see directly to the bottom, and both surface scum and the foul smells largely disappeared. Since the implementation of the submerged plants communities, no return of eutrophic conditions, even in hot weather, was observed. The submerged plants seem to have reduced turbulence within the water bodies, supported sedimentation and prevented sediment re-suspension, thus increasing transparency (Horppila and Nurminen, 2003). They also improved circulation of energy and gases (particularly oxygen) between water, sediments and plants, thus forming a healthier and more integrated system with higher phyto and bio remediative abilities.

\subsection{Main containments in the Dragon-shaped River}

After twelve months of monitoring the water quality in the nine sections, the results were as follows. Both the TN and TP values decreased progressively from W1 to W9, though results for $\mathrm{TN}$ were the most impressive. This decrease of $\mathrm{TN}$ and $\mathrm{TP}$ concentrations from section W1 to W9 was in accordance with expectations - reclaimed water fed in at the beginning of section W1 flows along from section W2 to W9, with

nutrient levels decreasing in each successive section (Figure 2). For TP concentration, as it was initially low (less than $0.4 \mathrm{mg} / \mathrm{L}$ ) in the reclaimed water in $\mathrm{W} 1$, measured reductions were smaller. The average TP concentrations in the sections from $\mathrm{W} 1$ to $\mathrm{W} 9$ 


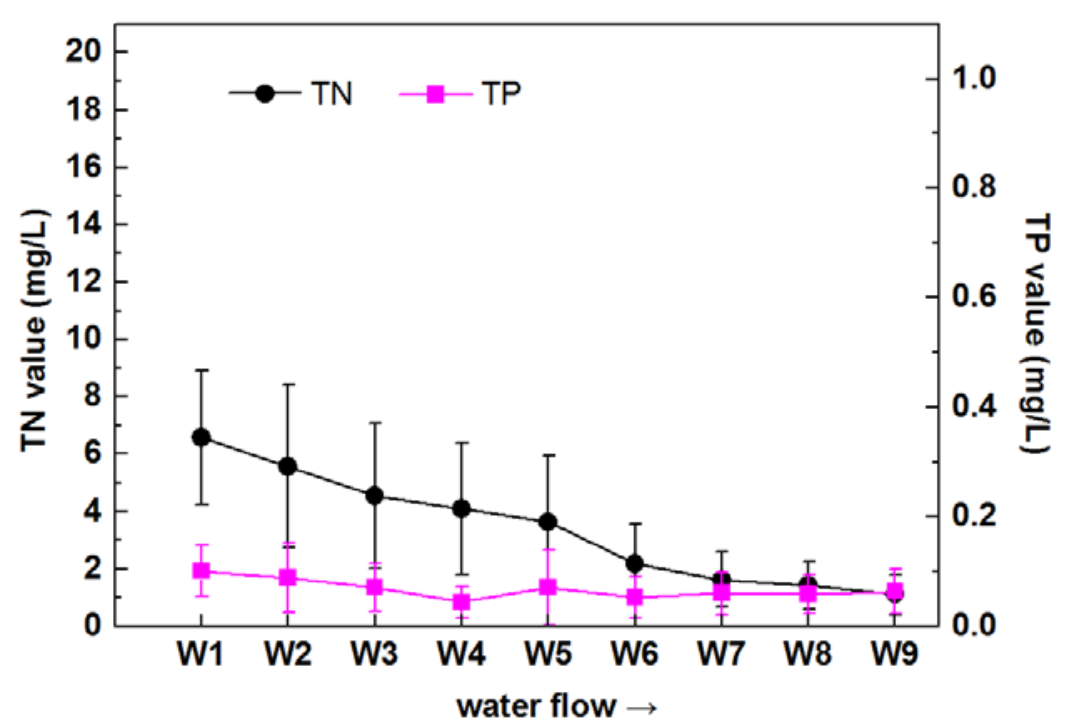

Figure 2: TN and TP change from W1 to W9

were normally below $0.1 \mathrm{mg} / \mathrm{L}$, which could meet the requirement of third class surface water quality in China (the standard for third class water is TP $\leq 0.2 \mathrm{mg} / \mathrm{L}$ ), indicating that the main contaminant in the Dragon-shaped River is nitrogen.

A closer look at TN concentration change from W1 and W9 was undertaken. Our data shows that the TN values obtained during the 12 month monitoring period fluctuated considerably. One of the possible reasons may be because of the non-point pollution by rainfall and resultant surface water runoff, especially from nutrient applications by horticulturalists and landscape managers. Seasonal effects related to the submerged plants system could also be explain some of this variation. Beijing's climate is characterized by a typical north temperate semi-humid continental monsoon climate, with hot and rainy summers and cold and dry winters. Both spring and autumn are relatively short. The TN concentration was relatively low coinciding with warmer summer temperatures. It appears that the sunshine and high temperatures of summer are good for plant growth and therefore for nutrient absorption and transformation. TN 
levels were usually higher at other times of the year.

Overall, we conclude that the installation of engineered plant communities has been successful in reducing eutrophication pressures in the Dragon-shaped River. There is however a consequence of considerable importance for the sustainability of the new system. Harvesting of aquatic plant biomass is very important in maintaining macrophytic plant communities' purification potency, thus regular management of submerged plants is essential or submerged macrophytes decomposition would release nitrogen back into the water body, resulting in reduced nitrogen removal efficiency (Feng et al., 2008; Vymazal, 2002; Vymazal J. \& Kröpfelová L. 2009) and increased COD and BOD. Timely harvest in summer could also contribute to a higher nutrient removal by promoting additional fresh growth, and therefore bioremediation.

In order to determine the bioavailability of different forms of nitrogen, ammonia levels were also monitored at each sampling point. Out data show that ammonia concentrations were very low compared with TN concentrations in all sections. Ammonia concentrations in all the samples were under, and usually well under, $1 \mathrm{mg} / \mathrm{L}$, which could meet the requirement of "third class" water according to the regulatory surface water standard used in China. It is already recognized that submerged macrophytes have a better nitrogen removal capacity compared to emergent macrophytes, because they can absorb nitrogen that is both dissolved in sediment and in water by root and body (Taguchi and Nakata, 2009; Kadlec, 2006). In the Dragon-shaped River, substances like nitrogen ( $\mathrm{TN}$ and $\left.\mathrm{NH}_{3}-\mathrm{N}\right)$ and phosphorus in reclaimed water can survive as necessary nutrients for submerged plants to grow and 
develop, some (such as ammonia) can be absorbed by plants directly, some can be utilized metabolically, thus decreasing residual contaminant volumes. The oxygen concentration decreased with depth, thus the availability of dissolved oxygen at the bottom is limited.

With the submerged plants in the water system, oxygen can be transferred by plant root, forming an aerobic-anoxic-anaerobic environment in the root zones, which provides conditions for formation of nitrite and nitrate from nitrogen. Therefore we conclude that initially TN concentrations (in W1, W2 and W3) are partly transformed by high nitrite and nitrate production, with ammonia concentrations remaining low.

Compared with nitrogen and phosphorus, COD levels in the water system were not similarly reduced from $\mathrm{W} 1$ to $\mathrm{W} 9$. COD concentrations from section W1 to W9 were quite static, and even showed some increase as surface run-off entered into the system. The highest COD concentration was in W6 - 106mg/L but observed values were mainly in a range of 20 to $40 \mathrm{mg} / \mathrm{L}$. COD removal is mainly dependent on the activity of microorganisms by the processes of aerobic or anaerobic degradation (Sani et al., 2013; Vymazal, 2002), but there are not enough filters in the submerged plants ecosystem for the formation of necessary biofilm, thus low or no COD removal is achieved. Based on the current eco-system, we suggest that a constructed wetland could be built along the river basin, in order to improve COD levels and reduce environmental risk (Zhang et al., 2014; Vymazal and Kröpfelová, 2009).

From the basic water parameter analysis in the Dragon-shaped River, it can be concluded that the water quality was improved with the implementation of engineered 
aquatic plant communities, but it is still hard to meet the requirement of the surface water standard, and there is still a risk of eutrophication related to surface run-off along the system. Nevertheless, with these aquatic plants in place the reclaimed water can safely be used to augment flows through the Dragon-shaped River and into the Dragon-shaped Lake. Therefore, the submerged plants played a key dual role in the Dragon-shaped River: removing nutrients, as well as inhibiting the growth of harmful algae.

\section{Issues and Challenges in Reclaimed Water Reused for Landscape Values}

The Dragon-shaped River is a good example of reclaimed water implementation in China, and its experience can be compared with similar projects elsewhere in China and around the world. However, our study shows that there are still persistent challenges, particularly relating to sustained nutrient removal across the broader spectrum (e.g. nitrates, nitrites, etc.) and the sustainable management of resulting plant biomass. As can be seen from the water quality analysis of the whole Dragon-shaped River, low or no COD removal was achieved through planting, so there is certainly a need for further re-engineering of the system with a view to reducing COD levels. Moreover, harvesting of submerged plants is an effective way to physically remove bioaccumulated nutrients (and other contaminants, e.g. metals) from the river. Indeed regular removal of biomass is necessary otherwise submerged macrophytes would eventually release nitrogen back into the water body during decomposition. Final disposal options for this submerged plant biomass (up to 10 tonnes during the summer season) are still under 
development however (Feng et al., 2008). The fresh harvested plants are rich in water, with moisture content of more than $90 \%$ and could be used as feedstock for anaerobic digestion-based methane recover. A better Another option might be co-composting with other wastes, not least because the harvested materials are rich in compost-friendly nutrients $(\mathrm{N}, \mathrm{P}, \mathrm{K})$. Without careful attention these system wastes could create potentially damaging leachate runoff and a perfect breeding ground for mosquitoes and flies. Study of the optimal management of harvested biomass from the Dragon-shaped River is currently being undertaken by the authors of this paper.

An additional problem follows from the under-recognized challenge of integrating wastewater reuse schemes into existing "conventional" treatment systems and also treated water discharge management systems. With respect to linking alternative water supply systems to conventional systems, one development path could be to disaggregate distribution of potable and non-potable supplies by creating a complete "dual" reticulation system. This is of course enormously expensive and disruptive. Another development path could be to upgrade treatment of wastewaters to the point where they meet Chinese government standards for drinking water - as yet a long way off. It is also not certain that increasing production of non-potable standard treated wastewater will necessarily compensate for increased abstractions and pollutant discharges and reduced natural inflows in the natural environment.

\section{Conclusions}

From this case study of Beijing's Dragon-shaped River system, it can be seen that 
without phytoremediation water quality struggles to meet the national environmental quality standards for surface water and actually tends towards eutrophic conditions. As more and more artificial lakes and rivers start to receive reclaimed water as a supplement to natural inflows, phytoremediation may be a useful option for avoiding eutrophication and attendant aesthetic problems. It is environmentally friendly and cost-effective to employ an engineered plant-based treatment system, and the management of Dragon-shaped River has proved to be success. Currently, however, there are no specific standards or regulations for such approaches to water quality management. There is also a need for design and engineering guidance appropriate to Chinese urban conditions. Thus, there is an urgent need for evidence-based guidelines for reclaimed water and sustainable landscape management, including the water quality control, landscape impact evaluation as well as life-cycle focused management of macrophytes in the ecological system. There is also an emerging debate about how such "decentralised” solutions can integrate with "centralised" solutions to best achieve water quality outcomes (Jensen and Yu, 2016) - the experience of the Dragon-shaped River could be quite instructive.

\section{Acknowledgement}

We gratefully acknowledge support from the International Water Security Network, funded by Lloyd's Register Foundation, a charitable foundation helping to protect life and property by supporting engineering-related education, public engagement, and the application of research. 


\section{References:}

Bixio D., Thoeye C., De Koning J., Joksimovic D., Savic D. \& Wintgens T. (2006). Wastewater reuse in Europe. Desalination, 187(1 - 3), 89-101. doi: 10.1016/j.desal.2005.04.070

Feng Z., Wen J., Jiang F., Deng Z. \& Lu X. (2008). Construction and Management of Artificial Ecosystem of the Dragon-shaped Olympic Water System in Beijing City (in Chinese). Wetland Science and Management, 33-36

Gross E. M., Erhard D. \& Iványi E. (2003). Allelopathic activity of Ceratophyllum demersum L. and Najas marina ssp. intermedia (Wolfgang) Casper. Hydrobiologia, 506-509(1-3), 583-589. doi: 10.1023/B:HYDR.0000008539.32622.91

Hilt S.\& Gross E. M. (2008a). Can allelopathically active submerged macrophytes stabilise clear-water states in shallow lakes? Basic and Applied Ecology, 9(4), 422-432. doi: 10.1016/j.baae.2007.04.003

Horppila J.\& Nurminen L. (2003). Effects of submerged macrophytes on sediment resuspension and internal phosphorus loading in Lake Hiidenvesi (southern Finland). Water Research, 37(18), 4468-4474. doi: 10.1016/S0043-1354(03)00405-6

Huertas E., Salgot M., Hollender J., Weber S., Dott W. \& Khan S. (2008). Key objectives for water reuse concepts. Desalination, 218(1 - 3), 120-131. doi: 10.1016/j.desal.2006.09.032

Jensen O. \& Yu X. (2016) Wastewater reuse in Beijing: an evolving hybrid system, International Journal of Water Resources Development, 32:4, 590-610, DOI: 10.1080/07900627.2016.1148589

Kadlec R. H. (2006). Free surface wetlands for phosphorus removal: The position of the Everglades Nutrient Removal Project. Ecological Engineering, 27(4), 361-379. doi: 10.1016/j.ecoleng.2006.05.019

Körner S. \& Nicklisch A. (2002). Allelopathic growth inhibition of selected phytoplankton species by submerged macrophytes1. Journal of Phycology, 38(5), 862-871

Li F.\&Hu H. (2004). Mechanism of phyto-allelochemicals and its application for harmful algae control in nature water body (in Chinese). Water \& Wastewater Engineering, 2, 1-4

Liu, S. \& Persson, K. M. (2013). Situations of water reuse in China. Water Policy, 15, $705-727$.

NBSC National Bureau Of Statistics Of China. (2016). China Statistical Yearbook 2016. Beijing, China.

Salgot M., Huertas E., Weber S., Dott W. \& Hollender J. (2006). Wastewater reuse and risk: definition of key objectives. Desalination, 187(1 - 3), 29-40. doi: 
10.1016/j.desal.2005.04.065

Sani A., Scholz M.\&Bouillon L. (2013). Seasonal assessment of experimental vertical-flow constructed wetlands treating domestic wastewater. Bioresource Technology, 147(0), 585-596. doi: 10.1016/j.biortech.2013.08.076

Soyupak S., Mukhallalati L., Yemi En D., Bayar A. \& Yurteri C. (1997). Evaluation of eutrophication control strategies for the Keban Dam reservoir. Ecological Modelling, 97(1 - 2), 99-110. doi: 10.1016/S0304-3800(96)00077-4

Staddon C. (2010) Managing Europe's Waters: $21^{\text {st }}$ century challenges, Ashgate.

Taguchi K. \& Nakata K. (2009). Evaluation of biological water purification functions of inland lakes using an aquatic ecosystem model. Ecological Modelling, 220(18), 2255-2271. doi: 10.1016/j.ecolmodel.2009.05.007

Vymazal J. (2002). The use of sub-surface constructed wetlands for wastewater treatment in the Czech Republic: 10 years experience. Ecological Engineering, 18(5), 633-646. doi: 10.1016/S0925-8574(02)00025-3

Vymazal J. \& Kröpfelová L. (2009). Removal of organics in constructed wetlands with horizontal sub-surface flow: A review of the field experience. Science of the Total Environment, 407(13), 3911-3922. doi: 10.1016/j.scitotenv.2008.08.032

Yi L., Jiao W., Chen X. \& Chen W. (2011). An overview of reclaimed water reuse in China. Journal of Environmental Sciences, 23(10), 1585-1593. doi: 10.1016/S1001-0742(10)60627-4

Zhang D. Q., Jinadasa K. B. S. N., Gersberg R. M., Liu Y., Ng W. J. \& Tan S. K. (2014). Application of constructed wetlands for wastewater treatment in developing countries - A review of recent developments (2000 - 2013). Journal of Environmental Management, 141(0), 116-131. doi: 10.1016/j.jenvman.2014.03.015 